\title{
O Papel do Ambiente no Pensamento Social Brasileiro: Contribuições a partir de Gilberto Freyre, SÉrgio BuARQue de Holanda e CaIo Prado JúNIOR
}

THE ROLE OF ENVIRONMENT IN BRAZILIAN SOCIAL THOUGHT: CONTRIBUTIONS FROM GILBERTO FREYRE, SÉRGIO

BUARQUE DE HOLANDA AND CAIO PRADO JÚNIOR

Márcia Helena Lopes* malena.lopes@gmail.com

Cristiane Gomes Barreto** crisgbarreto@gmail.com

André Vasques Vital ${ }^{* * *}$ vasques_vital@tutanota.com

RESUMO: O objetivo deste artigo é analisar o papel do ambiente nas interpretações do Brasil desenvolvidas por Gilberto Freyre, Sérgio Buarque de Holanda e Caio Prado Júnior. Destaca-se, trazendo para primeiro plano, como a natureza está presente na formação social brasileira, segundo esses autores. A leitura realizada do pensamento dos três intelectuais centra-se nas suas principais obras, lançadas entre os anos de 1933 e 1945: Casa Grande e Senzala (1933) e Nordeste (1937) de Gilberto Freyre, Raízes do Brasil (1936) e Monções (1945) de Sérgio Buarque de Holanda e Formação do Brasil Contemporâneo (1942) de Caio Prado Júnior. De maneiras distintas, os não humanos emergem nessas obras como personagens ativos na construção histórica da sociedade brasileira, em uma abordagem integrada e ainda importante para os debates envolvendo a dualidade culturanatureza no âmbito da História Ambiental.

PALAVRAS-CHAVE: natureza; formação social; materialismo cultural.

ABSTRACT: Our aim is to present an analysis about the role of environment on social thought from Gilberto Freyre, Sérgio Buarque de Holanda and Caio Prado Júnior. We highlight the role of the natural environment in Brazilian social formation. Our analysis of the thoughts of these three intellectuals regarded nature as the variable, instead of culture, which is hegemonic in the analytical tradition of the social sciences. The study of the works Casa Grande e Senzala (1933), Nordeste (1937) by Freyre, Raízes do Brasil (1936), Monções (1945) by Buarque de Holanda, and Formação do Brasil Contemporâneo (1942) by Prado Júnior showed that Nature appears as an active character in the historic building of the Brazilian society.

KEYWORDS: nature; social thought, cultural materialism.

\section{Introdução}

\footnotetext{
* Doutoranda do Programa de Pós-Graduação em Desenvolvimento Sustentável e Gestão da Biodiversidade do Centro de Desenvolvimento Sustentável da Universidade de Brasília (PPGDS - CDS). Mestre em Meio Ambiente e Desenvolvimento Sustentável pela L'Université Paris VII, 1999. Especialista em Direito Ambiental pela PUCGoiás 2003. Professora na Centro Universitário de Anápolis, UniEVANGELICA.

** Doutora em Política e Gestão Ambiental pelo Centro de Desenvolvimento Sustentável (CDS). Foi bolsista do Programa Nacional de Pós Doutorado (PNPD/Capes). Professora Adjunta do CDS-UnB. Professora Colaboradora do Programa de Pós-Graduação em Desenvolvimento Sustentável - UnB.

*** Doutor em História das Ciências e da Saúde, pelo Programa de História das Ciências e da Saúde (PPGHCS), Fiocruz. Atualmente cumpre estágio pós-doutoral com bolsa CAPES-PNPD no Centro Universitário de Anápolis GO, desenvolvendo trabalhos de pesquisa e docência no âmbito do Programa de Pós-Graduação em Sociedade, Tecnologia e Meio Ambiente (PPSTMA). É também pesquisador membro do Grupo de Pesquisa: Água, Saúde e Ambiente na História de Projetos de Desenvolvimento, da Fundação Oswaldo Cruz.
} 
Este artigo se insere no campo dos estudos das relações sociedade e ambiente. Esse é um campo relativamente recente no Brasil, pois os estudos da natureza, até a década de 1970, estiveram, em grande medida, circunscritos às chamadas ciências naturais. No entanto, a crescente compreensão de que a experiência social não é independente do meio natural no qual ela se insere tem instigado a investigação sobre o papel da natureza na vida humana (PÁDUA, 2005).

No âmbito do pensamento social brasileiro, várias narrativas destacaram como a natureza tropical exerceu uma influência sobre o ânimus social de um país em formação. Entre os intelectuais cujas ideias expressam essa perspectiva podemos destacar Sílvio Romero, Euclides da Cunha, Joaquim Nabuco, Alberto Torres, Paulo Prado, Gilberto Freyre, Sérgio Buarque de Holanda, Caio Prado Junior, Darcy Ribeiro, Roberto DaMatta. Cada um desses intelectuais, a seu modo, atribuiu à natureza um papel - integrador, determinista, econômico, desagregador, socializador, psicológico - na experiência de construção do Brasil.

Autores como Froehlich (2000), Pádua (2004), Murari (2005), Tavolaro (2008, 2011, 2013), Santos (2010, 2012), Ertzogue (2013), Losada (2016) têm investigado, na produção ensaística sobre o Brasil, referências a propósito da natureza tropical em articulação com os temas modernidade, cultura e crítica ecológica. Nessa seara, este artigo tem o objetivo de levantar contribuições centradas na interdependência entre humanos e não-humanos. Nos interessa colocar em perspectiva uma natureza que também é partícipe da organização e da construção social do País. Para tanto, apresentamos a leitura de obras, conhecidas pela sua importância na construção do pensamento social brasileiro, que fornecem elementos para uma compreensão mais integrada de sociedade e ambiente.

Dentro desse universo, optamos por trabalhar com os ensaios Casa Grande e Senzala (1933) e Nordeste (1937) de Gilberto Freyre, Raízes do Brasil (1936) e Monções (1945) de Sérgio Buarque de Holanda e Formação do Brasil Contemporâneo (1942) de Caio Prado Júnior. Dois aspectos foram considerados para este recorte metodológico.

O primeiro diz respeito à escolha dos autores. Gilberto Freyre, Sérgio Buarque de Holanda e Caio Prado Júnior pertencem à geração de intelectuais que se sobressaíram na década de 1930 e 1940 por adotarem uma nova perspectiva sobre os problemas brasileiros. Seus primeiros ensaios romperam com a tradição das interpretações inspiradas no positivismo oitocentista de Émile Littré e August Comte, e evolucionistas de Herbert Spencer e Ernst 
Haeckel, campo fecundo das teorias da raça e do determinismo biológico e geográfico. Influenciados por uma nascente sociologia universal alicerçada nas ideias de Karl Marx, Max Weber e Émile Durkheim, e pelo movimento modernista brasileiro, eles inauguraram uma interpretação autóctone do Brasil e defenderam a apreensão dos problemas brasileiros de dentro de sua própria história. Suas interpretações proporcionaram a abertura de novas possibilidades para a compreensão da história nacional, aspecto pelo qual suas obras ainda são consideradas extremamente importantes para o entendimento do Brasil enquanto nação.

O segundo aspecto refere-se à seleção das obras, que por sua vez está relacionado à factibilidade do trabalho. Em face da ampla produção bibliográfica dos autores escolhidos, decidimos adotar um recorte temporal analisando as principais obras de cada um no período entre o início dos anos 1930 e meados dos anos 1940. Essas obras possuem em comum o período histórico analisado pelos autores: o período colonial, compreendido como a gênese da formação social do Brasil.

Este artigo está organizado em quatro seções. Na primeira, avaliamos a relevância dos aspectos biofísicos nas obras Casa Grande e Senzala (1933) e Nordeste (1937) de Gilberto Freyre. Na segunda, nos debruçamos sobre as obras de Sérgio Buarque de Holanda: Raízes do Brasil (1936) e Monções (1945). A terceira seção é dedicada à Formação do Brasil Contemporâneo (1942) de Caio Prado Júnior. Por fim, na última seção, as contribuições dos autores são discutidas a partir de uma perspectiva material, salientando a sua importância no debate sobre perspectivas sociais e históricas menos dualistas e que podem ir além das narrativas centradas na destruição de sistemas naturais pelos humanos. Defendemos assim, que essas contribuições sociológicas, embora contendo alguns traços de determinismo ambiental, oferecem uma abordagem mais integrada e um rico e denso material sobre a relação dos brasileiros com o seu meio ambiente.

\section{A Natureza Tropical como Condicionante em Gilberto Freyre}

Em Casa Grande e Senzala, Gilberto Freyre analisa a sociedade brasileira por suas origens negra, indígena e europeia. Ele atribui à miscigenação o elemento chave da conquista do território brasileiro - um trópico desafiador e repulsivo aos olhos europeus. Nessa obra, Freyre dá destaque à natureza em vários trechos. São referências ao clima, solo, rios, fauna, flora e relevo e como esses elementos influenciaram a dieta, o comportamento, a sexualidade e a cultura do português, do índio e do negro. 
Inicialmente, a natureza da nova terra é descrita como um fator limitante à civilização, enfrentado pelo colonizador português em busca de enriquecimento rápido e prestígio. A princípio, a natureza tropical, como vista em outras colônias portuguesas, só tinha produtos extrativos a oferecer: ouro, prata, madeira, âmbar, marfim e especiarias. Ainda assim, o colonizador português teria, segundo o autor, inovado em terras tropicais, ao implantar uma técnica econômica e uma política social novas, antes só esboçadas nas suas colônias subtropicais insulares. Dessa forma, o rumo da colonização no Brasil mudaria do pragmático comércio mercantil para o sistema agrícola, com bases mais sólidas e condições mais estáveis. Desse modo, o colonizador português impôs a sua técnica, a despeito de ter uma "receita" determinística para colônias tropicais. Ele venceu o clima e o solo desfavoráveis.

Para Freyre, o sucesso do português estava no seu passado étnico e cultural, na sua predisposição à mestiçagem e na sua plasticidade. É certo que Freyre atribuía a aclimatabilidade portuguesa mais às origens étnicas do que à geografia ibérica, mas não deixava de valorizar o componente biofísico na sua narrativa. "Nas condições físicas de solo e de temperatura, Portugal é antes África do que Europa” (FREYRE, 2009, p. 72). O calor tropical provocava um "enlanguescimento" do homem do norte da Europa, seja no sul do Brasil ou no Havaí, ou seja, até mesmo em regiões subtropicais. Os europeus do Norte não conseguiam colonizar áreas tropicais a não ser por estabelecimentos temporários e que seus esforços eram fracassados e inúteis. Como exemplo, ele cita a tentativa malograda dos angloamericanos em conquistar as Bahamas, localizada em região tropical. Os primeiros empreendimentos foram similares entre os canaviais de Pernambuco e a as colônias inglesas de tabaco, algodão e arroz - baseados em "corajosa iniciativa particular" (FREYRE, 2009, p. 80).

De acordo com Freyre, "o ruralismo no Brasil não foi espontâneo, mas de adoção, imposto pelas circunstâncias" (FREYRE, 2009, p. 86). Essas circunstâncias são um conjunto de aspectos materiais, ligados à natureza tropical, que delinearam os modos produtivos e a cultura. Como exemplo, a qualidade de vida e a continuidade dos empreendimentos rurais estariam associadas à perenidade e à regularidade dos rios. Os rios não podiam ser muito grandes, pois extravasavam seu volume nas cheias devastando suas margens, mas também não poderiam ser muito pequenos, que secassem na estiagem. Os rios pequenos e perenes se prestavam como força motriz de muitos engenhos. Os rios navegáveis eram a condição 
favorável a disseminação do bandeirante para a conquista do interior. Assim, as condições hidrográficas tanto limitaram quanto favoreceram a dispersão para o interior, a instalação de vilas e engenhos, quanto influenciaram a economia de regiões favorecidas por rios estáveis e perenes.

Para Freyre, as condições biofísicas da América portuguesa teriam contribuído para unificar o estilo de vida colonial. "A ausência de um sistema de montanhas ou de rios verdadeiramente perturbador da unidade brasileira ou da reciprocidade cultural e econômica entre os extremos geográficos" criaram uma sociedade relativamente uniforme nos aspectos econômicos e sociais. (FREYRE, 2009, p. 117). Os antagonismos econômicos surgiram mais tarde, em reflexo às diferenças de capital de alguns senhores que conseguiram suportar a industrialização do açúcar, ou por antagonismos sustentados por novas formas de exploração econômica: o ouro na região central do País e o café em São Paulo. Outros antagonismos nasceram por imposição da geografia e da agricultura. Enquanto Pernambuco conservou o modo produtivo da grande propriedade monocultora açucareira, em São Paulo surgia um novo modo produtivo - a policultura. Foi somente na região subtropical, onde Freyre admite um condicionamento edafoclimatológico, que determinou o sucesso no tão desejado plantio regular do trigo. Esse foi um fato que diferenciou o tipo regional entre paulistas - mais eficientes e exitosos - do restante do País. Em São Paulo, a "superioridade de composição química do solo" gerava maior riqueza de produtos alimentícios. Em São Paulo, diferentemente do Rio de Janeiro e do Nordeste brasileiro, atuavam condições geológicas e meteorológicas mais favoráveis. A dieta teria influência no desenvolvimento físico e econômico das populações e nos diferenciava somática e psiquicamente dos europeus. Contudo, o modo produtivo latifundiário teria privado a população colonial de uma alimentação sadia e fresca. Faltava trigo, carne fresca, leite, ovos e legumes, exceto no planalto paulista.

Nos capítulos seguintes de Casa Grande e Senzala os relatos sobre a natureza permanecem muito presentes na descrição da culinária, dos utensílios da casa, das crenças indígenas, até no comportamento sexual e nas patologias. Nesses relatos, o meio biofísico atuou como condicionante e determinante da cultura material. Com isso, Freyre apresenta uma interpretação "sofisticadamente materialista, pois, parte das relações de produção para chegar às relações entre classes, às quais associa a relações étnicas" (ZARUR, 2015). Embora 
seja admitidamente rotulado como culturalista, Freyre usa com certa frequência métodos deterministas e materialistas para situar a sociedade em relação ao clima, ao solo e outras condições biofísicas. Além disso, corrobora inúmeras referências a deterministas e evolucionistas como Oliveira Viana, Benjamin Kidd, Ellssworth Huntington, Karl Sapper, dentre outros, para embasar suas análises.

Em Nordeste (1937) a importância do ambiente na história social é evidenciada desde a estrutura da obra, dividida em seis capítulos que contemplam a relação da cana de açúcar com cinco elementos: a terra, a água, a mata, os animais e o homem. A proposta de Freyre foi demonstrar o intercâmbio entre humanos e não humanos no que resultaria na sociedade patriarcal nordestina, a partir do que ele chamou "critério ecológico" (FREYRE, 2004, p. 37).

Nordeste colocou o massapê nos glossários sociológicos, descreveu e classificou os "rios de açúcar", explicou a geografia dos engenhos condicionada pelos rios, pelo solo e pela pluviosidade da Zona da Mata. O autor demonstrou, precocemente, uma preocupação ecológica com o tratamento dado aos rios e condenou a devastação das matas. Ressaltou a falta de intimidade do colono branco com o ambiente, contrariamente do negro, que teria se adaptado à floresta com um "máximo de aproveitamento da vida nativa" (FREYRE, 2004, p. 89). A partir do contexto do engenho, Freyre percebeu e descreveu o processo de enfraquecimento dos laços entre humanos e não humanos, como resultado da modernização e da industrialização da cultura canavieira. Esse processo teria causado um "desajustamento de relações entre a massa humana e o açúcar, entre a cana-de-açúcar e a natureza" (FREYRE, 2004, p. 178). E ainda alertou:

(...) não se brinca em vão, ou sem correr algum risco sério, com a vida vegetal de uma região; que está, afetada na sua interdependência de relações por planta estranha ou por animal intruso, que se torne predominante, pode desequilibrar-se a ponto de perturbar o próprio homem na sua economia e nas suas fontes mais puras de subsistência. É lição dos ecologistas, e não simples grito de alarme dos sociólogos românticos. (FREYRE, 2004, p. 84).

Freyre situa a monocultura canavieira, como representação do modo produtivo, entre a natureza - da Mata Atlântica nordestina - e a sociedade açucareira. Nesse processo, o ambiente biofísico teria determinado o modo produtivo canavieiro que, por sua vez, modelara a sociedade do Nordeste açucareiro de maneira peculiar. Independente das origens do colonizador, esse processo se repetiria em outras colônias da América Central: Barbados, Jamaica, Trinidad e Cuba; que de similar ao Nordeste teriam o ambiente tropical e a estrutura 
social resultante "apesar da religião e da raça tão diferentes de seus colonos (...)" (FREYRE, 2004, p. 40). O meio produziria, portanto, paisagens e sistemas sociais muito similares.

Assim, Nordeste é uma obra que salienta o estudo do ambiente como uma infraestrutura para a compreensão do sistema social. Não haveria "nada mais importante no estudo do homem que as suas relações com a água, [esta é] a nota dominante na vida da paisagem. Da paisagem física como da cultural" (FREYRE, 2004, p. 57). Segundo Duarte (2005a), o seu objetivo foi ressaltar as inter-relações possíveis entre a "natureza que é expressão cultural, homem que é também natureza; região que traz no solo, na vegetação e na vida animal a marca do povo que a habita, sociedade que se constrói adaptando-se à região sempre transformada" (DUARTE, 2005a, p. 129).

Freyre trafega entre o mapeamento da paisagem e seus elementos (solo, água, plantas e animais) e a descrição da sociedade. Nesse caminho, ele costura relações causais, valorizando o que a paisagem fornece à sociedade e como ela utiliza esses elementos no Nordeste açucareiro. Nesse sentido, o ambiente material ganha relevância na produção de Freyre, onde é ressaltado o papel dos não humanos na história social, formando uma abordagem mais integrada.

\section{A Natureza como Personagem em Sérgio Buarque de Holanda}

O ponto de partida de Sérgio Buarque em Raízes do Brasil (1936) para traçar a sua análise da sociedade é o fato de sermos marcados pelo sentimento de exilados em nossa própria terra. Esse sentimento expressa a ruptura originária entre a cultura e a natureza, sobre a qual se constituiu a nossa experiência. A natureza é a tropical, imponente, grandiosa, mas também hostil e ameaçadora; a cultura é a Ibérica, um tanto quanto marginal ao restante da Europa, mas ao mesmo tempo a ela ligada. A transposição das formas de convívio social, das instituições, sensibilidades e visões de mundo dessa cultura europeia se revelava um empreendimento improvável, somente precariamente realizável, em face das particularidades do ambiente em um território singular e desconhecido. O ensaísta atribui o sucesso desse empreendimento a uma característica cultural: a habilidade ímpar do colonizador para adaptar-se aos trópicos.

A Península Ibérica, de matriz cultural mestiça - nem absolutamente ocidental, nem oriental - produziu o tipo português dotado de uma plasticidade social que permitia moldar- 
se às condições do meio e a outras culturas. Essa habilidade é interpretada como a qualidade determinante para a consolidação da civilização sui generis que é a brasileira. Na obra, a adaptabilidade é apresentada em contraposição às condições hostis do ambiente indicando a força da natureza na forja do futuro brasileiro. Em um primeiro momento, a natureza é um obstáculo tão grandioso que exige uma adaptação a ela, impondo novas formas de sobrevivência. Assim, o clima, o relevo, o tipo de solo, a fauna, a flora e os minérios definiram os contornos de novos hábitos alimentares, de habitação e de locomoção. A hostilidade da natureza tropical restringiu a implantação da cultura europeia, pois não havia modo de estabelecer na colônia portuguesa as mesmas condições materiais e culturais do Velho Mundo. O Brasil nasceu desse limbo, nem lá nem cá. Para Buarque de Holanda, aí repousa a origem de nossa singularidade, o traço principal de nossa cultura.

Em Raízes do Brasil a colonização dos trópicos é apresentada como uma aventura, onde a riqueza é o grande prêmio. Assim, todo o empreendimento esteve voltado para objetivos imediatos de exploração econômica nas novas terras. A lógica da aventura marcou o passo do processo civilizatório, o que ficou registrado no modo devastador como a terra foi explorada. A abundância de recursos naturais em um território de proporções gigantescas, se comparado ao de Portugal, foi percebida como fonte perene de fortuna. Da extração de madeira das primeiras décadas ao desenvolvimento de uma sociedade tipicamente rural (e não agrária), passando pelas incursões no sertão em busca de produtos da floresta, a atividade econômica sempre possuiu um caráter imediatista e predatório, operada pelas demandas de um mercado externo. $\mathrm{O}$ modelo de agricultura que se estabeleceu na colônia com a cana de açúcar não teria contribuído para criar um vínculo afetivo do colonizador com a terra, já que estava alicerçado no trabalho escravo, que por sua vez, era quem efetivamente estava em contato com o meio biofísico.

O descaso com que o português se relacionava com o ambiente foi entendido por Buarque de Holanda como resultado da lei do menor esforço. Nas suas palavras "o que o português vinha buscar era, sem dúvida, a riqueza, mas a riqueza que custa ousadia, não a riqueza que custa trabalho" (BUARQUE DE HOLANDA, 2014, p.56). Pela lógica do aventureiro, a exploração intensiva fazia todo sentido - retirar, sem nada repor. Em relação à agricultura, o autor reconhece que a tropicalidade do ambiente oferecia dificuldades ao seu manejo, exigindo uma disposição para inovações, não afeita ao perfil passivo do português. Além disso, 
a dimensão continental da colônia, que proporcionava uma grande disponibilidade de terras "livres", estimulou o caráter predatório da agricultura, já que a derrubada de matas virgens era uma prática comum, por ser mais rentável do que o manejo de terras já desmatadas. Buarque de Holanda chega a sugerir que aqui se praticou uma espécie de mineração do solo.

A verdade é que a grande lavoura, conforme se praticou e ainda se pratica no Brasil, participa, por sua natureza perdulária, quase tanto da mineração quanto da agricultura. Sem braço escravo e terra farta, terra para gastar e arruinar, não para proteger ciosamente, ela seria irrealizável (BUARQUE DE HOLANDA, 2014, p. 56).

Entendemos que Raízes do Brasil apresenta dois eixos interligados onde podemos situar o papel da natureza. O primeiro se refere à natureza como obstáculo à transposição de uma civilização nos moldes europeus para o continente americano. A sobrevivência e a construção de uma sociedade nos trópicos demandaram uma outra relação entre humanos e não humanos, exigindo uma capacidade de adequação aos caprichos de um ambiente estranho e agressivo para o padrão europeu. Assim, a natureza teria selecionado o "tipo" colonizador e os seus modos produtivos. O segundo envolve o modo predatório de exploração econômica da colônia, tendo a natureza como uma fonte de riqueza inesgotável. Logo de partida, o sucesso da colonização esteve associado a uma economia extrativista. O desenvolvimento econômico da colônia ocorreu com base no desmatamento da faixa de floresta litorânea, no empobrecimento e desgaste dos solos mais férteis, na degradação de matas e rios pela exploração de minérios.

Em Monções, livro publicado em 1945, Buarque de Holanda volta ao período colonial para analisar o processo de ocupação do Oeste brasileiro a partir de expedições fluviais - as monções - que partiam de São Paulo em direção às minas de Cuiabá. A importância dos rios para o desenvolvimento das regiões interioranas é densamente descrita pelo autor na movimentação fluvial de exploradores, colonizadores e comerciantes nas bacias hidrográficas do rio Paraná e do rio Paraguai. O movimento da fronteira interna de ocupação por penetração fluvial é uma característica inerente à formação do território paulista. Para isso, a hidrografia daquela região, onde boa parte dos rios navegáveis correm para o oeste, contribuiu para a interiorização da ocupação.

Outro elemento importante de ordem ambiental, destacado por Buarque de Holanda, é a característica do relevo paulista cuja linha litorânea é cortada pela Serra do Mar, que impedia um contato mais fluente do interior com essa faixa, centro econômico e político 
da colônia. Dessa forma, o relevo foi um fator que direcionou a expansão paulista para o interior.

\begin{abstract}
A mobilidade dos paulistas estava condicionada, em grande parte, a certa insuficiência do meio em que viviam; (...). Distanciados dos centros de consumo, incapacitados, por isso, de importar em apreciável escala os negros africanos, eles deverão contentar-se com o braço indígena - "os negros" da terra; para obtê-los é que são forçados a correr sertões inóspitos e ignorados (BUARQUE DE HOLANDA, 2000, p .16.)
\end{abstract}

As peculiaridades ambientais seriam um fator determinante de uma certa vocação para o movimento. A formação de São Paulo é vista em contraste com a do Nordeste; neste se assentava a ordem agrária, naquele o impulso da fronteira.

Se em Raízes a natureza se limitava a ser fonte de recursos, seguindo a ordem do baixo esforço e do enriquecimento rápido, característico da aventura, em Monções os rios e as jornadas fluviais moldaram os costumes, pois "tiveram uma ação disciplinadora e de algum modo amortecedora sobre o ânimo tradicionalmente aventuroso daqueles homens" (BUARQUE DE HOLANDA, 2000, p. 72). O convívio intenso com o sertão hostil demandou um aprendizado mais paciente e contínuo. As monções exigiram uma proximidade maior do conquistador com a natureza, seja para dominar técnicas ou adotar práticas e hábitos dos nativos que lhes permitissem adentrar o território.

A narrativa de Monções é rica em referências às condições do ambiente a que os viajantes do sertão estavam expostos e eram desafiados a adaptar-se. O clima foi um fator importante ao avanço das monções. Os longos períodos de seca e chuva definiam o momento, e as vezes a duração das viagens. As características dos rios determinavam a rota e o tipo de embarcação adotada. Os rios de águas muito agitadas e encachoeirados eram geralmente evitados, em prol de cursos mais suaves e navegáveis ${ }^{1}$. A vegetação local favorecia, ou não, os tipos de embarcações adotados. A canoa de casca, de origem indígena, foi largamente utilizada no território brasileiro, em especial nos cursos dos rios de leito muito acidentado. Segundo Buarque de Holanda (2000), onde houvesse mato, certamente encontrava-se arvoredo adequado para a fabricação desse tipo de embarcação. As canoas de tronco inteiriço chamadas ubás (no Norte) ou pirogas (em São Paulo) foram adotadas na região do Tietê onde

\footnotetext{
${ }^{1}$ No entanto, alguns cursos extremamente difíceis como o do rio Pardo foram intensamente utilizados. Isto ocorreu por uma questão de segurança, já que outros cursos mais fáceis eram mais vulneráveis aos ataques dos índios da região.
} 
a formação florestal oferecia madeiras leves e árvores grandes. Uma posterior redução nas dimensões e na capacidade das pirogas, e até mesmo o seu desuso foi associado à uma provável escassez de árvores de tamanho adequado, decorrente da exploração intensiva das florestas, mas também do uso do sistema de queimadas para as lavouras nos povoamentos.

Lançados aos sertões inóspitos, expostos aos ataques de povos indígenas, os viajantes com frequência dependeram da riqueza animal, da fartura de peixes e plantas nativas para sua alimentação e medicação. A caça e a pesca eram atividades comuns e complementares à precária agricultura praticada nos povoamentos dispersos ao longo dos rios. A apropriação de aspectos da cultura e da vida material do nativo, maior conhecedor do ambiente local, pelo adventício teve um papel primordial no processo de interiorização da população. Assim, a natureza torna-se protagonista na história narrada por Buarque de Holanda. Seja limitando, desafiando ou favorecendo os empreendimentos humanos, ou ainda, sofrendo os impactos humanos, a flora, a fauna, os cursos fluviais, o solo e o clima também condicionaram os rumos da civilização brasileira. Mais do que influenciar a cultura material, o meio biofísico teria influenciado o comportamento e a mentalidade do monçoeiro.

Não é só o emprego de meios de locomoção diversos, é, também, e principalmente, o complexo de atitudes e comportamentos, determinados por cada um desses meios, o que fará compreender a distinção essencial entre a primitiva bandeira e a monção de povoado. Naquela, os rios constituem, efetivamente, obstáculos à marcha, e as embarcações são apenas o recurso ocasional do sertanista, utilizável onde a marcha se tornou impossível. Nas monções ao contrário, a navegação, disciplinadora e cerceadora dos movimentos, é que torna regra geral, e a marcha a pé, ou a cavalo, ou em carruagem, constitui exceção a essa regra. (BUARQUE DE HOLANDA, 2000, p. 72-73).

O processo das monções não deixou marcas duráveis nos hábitos dos paulistas, embora tenha pontuado o povoamento interior. "A psicologia de nossa gente rude não a acomodava aos rios, como não a acomodou verdadeiramente ao solo" (BUARQUE DE HOLANDA, 2000, p. 69). A relação predatória com o ambiente é apontada como o reflexo de um sistema social fragilmente conectado ao sistema natural e de uma cultura material instável e imatura.

\section{A Onipresença da Natureza em Caio Prado Junior}

O ensaio Formação do Brasil Contemporâneo (1942) não é a obra inaugural de Caio Prado Júnior, mas é considerado o seu trabalho mais relevante do ponto de vista de uma 
contribuição inovadora ao pensamento social brasileiro. Para o objetivo deste trabalho, Formação do Brasil Contemporâneo revela um panorama onde a natureza é uma presença constante. O autor utiliza-se largamente da geografia para situar o processo de estabelecimento da empresa colonial nos trópicos americanos. Ele examina de que maneira fatores como o clima, a vegetação, o relevo e os tipos de solos influenciaram na formação da vida econômica da colônia. Talvez essa abordagem decorra da própria experiência do autor que transitou por vários campos do conhecimento, inclusive nas ciências naturais (IUMATTI, 2000).

A tese mais famosa de Prado Júnior é a que situa a colonização do Brasil em um quadro mais amplo do desenvolvimento do capitalismo mercantil europeu que, a partir do século XV, ganhou novos contornos com a evolução da navegação marítima. A natureza tem um papel relevante no "sentido da colonização" defendido pelo autor, já que à empresa colonial interessava as riquezas naturais das terras além mar. O modelo de colônia de exploração, aqui instalado, seria a porta de entrada para o debate futuro sobre a natureza tropical e a nossa dependência econômica.

Para Prado Júnior, a condição geográfica e as características ambientais de Portugal os teriam colocado à frente das demais nações na navegação mercantil. De um lado possuíam uma expressiva costa oceânica. "o papel pioneiro nessa nova etapa [do comércio ultramarino] caberá aos portugueses, os melhores situados, geograficamente, no extremo desta península que avança pelo mar" (PRADO JR., 2011, p.18). De outro, um território pequeno e pouco agrícola, que os impelia ao movimento da grande fronteira.

Os fatores ambientais são destacados pelo autor ora como força motriz, ora como verdadeira limitação ao desenvolvimento da colônia. Um aspecto importante é a relação entre recursos naturais disponíveis, utilidade econômica e dinâmica de ocupação. Três fases ou momentos distintos são apontados por Prado Jr.: (1) a ocupação do litoral, inicialmente associada à exploração da madeira pau-brasil, e posteriormente ao cultivo intensivo da canade-açúcar; (2) a expansão da fronteira interior impulsionada pela mineração; (3) o retorno ao litoral - associado ao desenvolvimento de uma agricultura mais consolidada. Cada novo ciclo econômico comandou a abertura de uma nova fronteira interna, ou intensificou outras existentes. 
A faixa litorânea recebeu a primeira leva da população, que ali permaneceu concentrada. Essa faixa apresentava fatores ambientais vantajosos às atividades agroexportadoras: "solo fértil, relevo propício, abundância de matas fornecedoras de combustível e bom material de construção" (PRADO JÚNIOR, 2011, p. 39). As terras férteis e o clima úmido litorâneo favoreceram a introdução do cultivo da cana, cujo principal subproduto, o açúcar, foi por muito tempo a vedete da colônia. Por suas qualidades ambientais a grande lavoura se estabeleceu nessa faixa, adentrando pouco as terras interiores.

A ocupação do litoral brasileiro não foi uniforme, criou poucos pontos de concentração demográfica e muitos espaços completamente vazios. Prado, deliberadamente atribuiu à obra da natureza esse perfil de ocupação:

Os fatores naturais que construíram a costa brasileira intervêm aí claramente. Em conjunto, nosso litoral se apresenta pouco favorável ao estabelecimento do homem; desenvolve-se numa linha regular e uniforme, quase sem sinuosidades ou endentações. Os abrigos, mesmo para pequenas embarcações, são escassos; além disso, a orla marítima é bordada, em regra, quando não por terrenos alagadiços - os manguezais, invadidos pela água salgada na preamar e pelo despejo dos rios na vazante - por grandes depósitos arenosos que obstruem as brechas abertas para o interior das terras: a barra dos rios ou as lagunas. Os raros pontos favoráveis foram por isso avidamente aproveitados, e neles se condensou a população. (PRADO JR., 2011, p. 39)

Ele destaca as características ambientais da costa do Nordeste, entre os atuais estados do Rio Grande do Norte e Alagoas, como extremamente favoráveis à navegação. Somando a esse fato, a qualidade do solo e o clima propício para agricultura, faria dessa faixa, uma área próspera.

A mineração foi a mola propulsora da interiorização do povoamento. O ouro orientou a penetração no território, superando as barreiras naturais que separavam o litoral "civilizado", do sertão "selvagem". A mineração empurrou a linha da fronteira interna, alcançando a região central, nos territórios atuais de Minas Gerais, Mato Grosso e Goiás. No entanto, esse avanço não ocorreu de forma contínua. Ao contrário, se configurou como um "salto", produzindo grandes vazios demográficos. Esta seria uma característica do modelo de ocupação do território brasileiro: uma marcante descontinuidade oriunda da mineração, somada a uma estrutura fundiária baseada na grande propriedade rural. 
Em geral, a vegetação tropical, normalmente de difícil penetração, foi um dos fatores ambientais considerados pelo autor para o isolamento de determinadas regiões interiores. Segundo Prado Jr (2011), as densas florestas da região de Minas Gerais, durante o ciclo da mineração, tiveram um papel importante servindo como barreiras aos caminhos marginais do sertão pelos quais circulavam o ouro contrabandeado. Em determinadas localidades da província as florestas que separavam núcleos mineradores, foram deliberadamente preservadas para que "protegessem" o ouro da Coroa dos possíveis descaminhos (PRADO, 2011).

Para além da degradação própria da atividade de mineração, a decadência do ciclo do ouro provocou significativa alteração no conjunto da paisagem das regiões auríferas. A agricultura e a pecuária substituíram a mineração como principais atividades produtivas no sertão. Aquelas regiões cujos solos eram mais propícios ao cultivo e à pecuária, incorporaram maiores contingentes de pessoas oriundas das antigas minas. Na região de Goiás, segundo Prado, o solo mais ácido e de difícil cultivo limitou o desenvolvimento de uma agricultura mais rentável, e a principal atividade econômica que se estabeleceu foi a pecuária. Sua relativa lucratividade advinha mais das extensas pastagens naturais e das bancadas de solo salobro que reduziam consideravelmente os custos de produção, do que da qualidade do gado.

Segundo o autor, os aspectos biofísicos em algumas regiões do Brasil favoreceram o desenvolvimento da pecuária como uma das principais atividades econômicas voltadas ao mercado interno. São apontadas três importantes áreas onde a criação aconteceu na dependência das particularidades ambientais: (1) o sertão do Norte (Nordeste), (2) a parte meridional de Minas Gerais e (3) as planícies do Sul. No sertão, a vegetação pouco densa da caatinga, o relevo quase plano e os afloramentos salinos foram fatores positivos para o desenvolvimento da pecuária bovina, enquanto a falta de água foi o seu principal obstáculo. Nas palavras de Prado Jr., "A recorrência das secas, que se sucedem no século XVIII em períodos mais ou menos espaçados, mas com regularidade dramática, vai destruindo as fontes de vida destas infelizes regiões" (PRADO JR., 2011, p. 206).

$\mathrm{Na}$ parte meridional de Minas Gerais, as condições ambientais favoreceram o desenvolvimento de uma pecuária de melhor qualidade. $O$ primeiro aspecto ressaltado é a abundância de águas, com a presença de rios caudalosos e perenes. A boa pluviosidade e a boa forragem, esta última, consequência das características da vegetação local, são outros 
elementos positivos. Fica ressalvado apenas o relevo acidentado, mas que em algumas localidades oferece "terrenos apenas ondulados" (PRADO JR., 2011, p. 207). A abundância de outros elementos, como madeira e certos tipos de rochas, facilitaram a introdução de cuidados com o gado, utilizando-se currais de pedra ou cerca de madeira para o confinamento do rebanho, além do uso de pastos cercados.

Nos campos sulinos, onde nas palavras do autor, "aparecem condições naturais admiráveis" (PRADO JR, 2011, p.213), o papel do ambiente é destacado como elemento ativo no desenvolvimento da atividade. A topografia, a vegetação, as pastagens, levemente salinizadas por força dos ventos marítimos e a abundância de águas beneficiaram a atividade pecuária. "Em suma, a pecuária rio-grandense nada tem de particularmente cuidadosa; é a natureza propícia que realiza o melhor, e o homem confia mais nela que em seus esforços" (PRADO JR., 2011, p. 218).

Prado ressalta como os fatores geográficos interferiram no estabelecimento de uma rede de comunicação eficiente na colônia. O que, na visão do autor, conduziu ao caráter indolente de nossa sociedade.

As distâncias enormes, os obstáculos ao trânsito num território como o nosso, de relevo acidentado, de coberturas florestais, nos pontos estratégicos, de difícil penetração, com uma linha costeira tão parcamente endentada e rios, com poucas exceções, de cursos cheios de acidente e traçado infeliz, para os rumos que a colonização tomou; de tudo isso vão resultar comunicações difíceis e morosas que imprimem às relações da colônia um ritmo lento e retardado; e que terá tido com toda a segurança um boa dose de responsabilidade nesse tom geral de vida frouxa que caracteriza o país. (PRADO JR, 2011, p.251)

As vias marítima e fluvial funcionaram como elementos unificadores da rede interna de comunicação, já que não existia ligação entre as várias rotas (sistemas autônomos) que conectavam o interior ao litoral, e vice-versa. No entanto, a navegação de cabotagem, por exemplo, era limitada pela direção dos ventos, que permitia maior fluxo em um sentido do que em outro. Prado ilustra bem essa questão ao destacar a importância de uma determinada linha de comunicação terrestre para o desenvolvimento do Maranhão.

Estabelecida finalmente uma ligação em linha direta de costa a costa, entre dois dos mais importantes núcleos litorâneos: Bahia e Maranhão. Ligação tanto mais importante que os ventos contrários reinantes na costa dificultavam sobremaneira as comunicações por mar desta última capitania com as demais que the ficavam para o sul. (PRADO JR, 2011, p.256) 
Com a interiorização da ocupação as vias de comunicação que partiam do litoral, em pontos distantes entre si, tendiam a convergir no interior. Duas circunstâncias geográficas são apontadas por Prado para esta configuração. A primeira, referindo-se ao caso do Nordeste brasileiro, decorre da abrupta mudança de direção da linha costeira na altura de 50ㅇ de Lat. S., fazendo com que linhas de penetração que partiam da costa leste e da costa norte em direção ao interior naturalmente se encontrassem. A segunda circunstância estava ligada ao curso dos rios e ao traçado do relevo brasileiro, que direcionavam o movimento de penetração e povoamento, pois estes se aproximavam das cabeceiras das bacias (PRADO, 2011, p. 252).

Muitos são os aspectos em Formação do Brasil Contemporâneo que revelam como o ambiente teve uma participação ativa na constituição da colônia. A colonização foi sendo moldada dentro das condições oferecidas pela natureza, muitas das quais o colonizador teve de superar ou contornar. Por vezes, essa natureza impôs dificuldades, limitações, impedimentos, por vezes, operou como elemento facilitador, motivador, vantajoso.

\section{Ambiente e Construção Social}

A leitura desses clássicos, a partir de uma perspectiva ambiental, revelou que a paisagem emerge na bibliografia desses intelectuais não só como pano de fundo, mas como elemento participativo da construção da nação brasileira. A variável ambiental tem maior relevo nas obras Nordeste, Monções e Formação do Brasil Contemporâneo. Essas duas primeiras obras têm pouca ressonância nos estudos das ciências sociais, mas revelam novas abordagens teórico-metodológicas e maior maturidade intelectual dos seus autores. No geral, são obras que adquiriam maior repercussão recentemente (LIMA, 2011).

Embora Freyre seja reconhecido pelo seu relativismo, antagonismos em equilíbrio, ele não rompeu absolutamente com a interpretação determinista. Especialmente em Nordeste, ele reconheceu que o ambiente exerce influências significativas sobre a sociedade. Para tanto, Freyre promoveu um diálogo entre o campo material e simbólico. Mas teve o cuidado de limitar a universalidade do materialismo cultural, por um lado reconhecendo os efeitos biofísicos diferenciados sobre as raças, mas por outro lado, argumentando que a miscigenação não é deletéria como alegavam os deterministas e evolucionistas. Freyre não admite uma hierarquia de raças, mas, por outro lado, defende a tese da adaptabilidade condicionada pelos aspectos biofísicos e culturais. 
Tanto Freyre como Buarque de Holanda e Prado Jr. mostram que há uma dinâmica na influência do natural no social. De forma mais evidente, Prado Jr. fundamenta toda a sua análise social e histórica sobre a influência de fatores ambientais, tomando as relações sociais como indissociáveis das relações humanos-natureza (DUARTE, 2005b). Freyre e Buarque de Holanda reconhecem por um lado o fator constritivo das condições biofísicas tropicais na seleção do "tipo ideal" para colonizar o Brasil e por outro lado, esse tipo sendo o único personagem com características necessárias para se adaptar ao ambiente tropical. Se em Freyre esse "tipo" é substituído pela família rural patriarcal, em Buarque de Holanda, ele se "reproduz" na sociedade.

Para Freyre, a natureza perderia parte da sua influência após a fase de colonização inicial, até 1532, quando se inicia uma política formal da Coroa portuguesa para a colonização. Somente a partir disso, passaria a processar a "verdadeira formação social" do País, baseada na família rural. Até o século XIX a natureza era vista como um obstáculo a ser transposto. Era a natureza de fronteira: a ser dominada e seus elementos transformados em recurso. Se por um lado os três autores reconhecem a tendência que a natureza tem no sentido de recriar à sua imagem os indivíduos, também ressaltam a existência dos recursos técnicos em sentido contrário.

Essa abordagem aproxima os autores do materialismo cultural (HARRIS, 2011), cujo determinismo é probabilístico e compatível com as intencionalidades dos indivíduos de controlar seus destinos, e auxilia no entendimento das origens das diferenças e similaridades entre sociedades e culturas, baseando-se na premissa de que a vida humana social é um resultado de problemas práticos enfrentados no meio. Há um alinhamento com o materialismo dialético, mas com a adição de mais variáveis ecológicas à conjunção de condições materiais.

Nesse sentido, o ambiente é necessário para pensar na existência (construção da identidade) de uma sociedade. Em outras palavras, as excepcionalidades humanas existem em interdependência com os objetos materiais. O sistema social abrange a cultura material e, portanto, a análise do social deve incorporar os aspectos da paisagem no qual os homens vivem, o ambiente no qual se desenvolvem as relações humanas. Dessa forma, os argumentos ecológicos e geográficos, sejam eles determinísticos, possibilísticos, relativistas ou causais, permanecem relevantes para a história sociocultural do País. 


\section{REFERÊNCIAS BIBLIOGRÁFICAS}

BARRETO, Cristiane Gomes e CEZAR, Kilma Gonçalves. 2012. A Colonização e os Modos de Produção na Mata Atlântica Nordestina sob a Ótica do Materialismo Histórico. Revista Econômica do Nordeste, v. 43, p. 313-323, 2012.

BUARQUE DE HOLANDA, Sérgio. Raízes do Brasil. São Paulo: Companhia das Letras, 2014. . Monções. São Paulo: Brasiliense, 2000.

BURKE, Peter. 1997. Gilberto Freyre e a nova história. Tempo Social; Rev. Sociol. USP, S. Paulo, 9(2): 112, outubro de 1997.

CARVALHO, Adriana Duarte de Souza. 2011. A Teoria Weberiana na Invenção do Brasil: uma Análise de Raízes do Brasil de Sérgio Buarque de Holanda. Intratextos, Rio de Janeiro, 3(1): 80-92, 2011

CATTON, William R. e DUNLAP, R. 1980. A new ecological paradigm for post exuberant sociology. American Behavioral Scientist, vol. 24, p. 15-47.

CHILDE, V. Gordon. 1951. Man makes himself. Rev. ed. New York, 1951.

DAMATTA, R. Em torno da representação da natureza no Brasil: pensamentos, fantasias e divagações. In: BOURG, Dominique. Os sentimentos da natureza. Lisboa: Perspectivas ecológicas, 1993.

DIAMOND, Jared. 2014 [1997]. Armas, Germes e Aço. 17ạ ed. Rio de Janeiro, RJ: Record, 2014.

DRUMMOND, José Augusto. 1990. A história ambiental: temas, fontes e linhas de pesquisa. Estudos Históricos, 1990.

DUARTE, Regina Horta. 2005a. "Com açúcar, com afeto": impressões do Brasil em Nordeste de Gilberto Freyre. Tempo, Rio de Janeiro, № 19, pp. 125-147.

2005b. História \& Natureza. Belo Horizonte: Autêntica, 2005.

ERTZOGUE, Marina Haizenreder. "Amanhã anda a roda" natureza e sensibilidade em Cartas de Petrópolis de Joaquim Nabuco. Varia História, Belo Horizonte, vol. 29, oㅡ 50, p.513-529, mai/ago 2013.

FREYRE, Gilberto. Casa Grande e Senzala. Rio de Janeiro: Global, 2009.

Nordeste. Aspectos da Influência da Cana sobre a Vida e a Paisagem do Nordeste. 2004.

FROEHLICH, J. M. Gilberto Freyre, a História ambiental e a 'Rurbanização'. História Ciências Saúde Manguinhos. Rio de Janeiro: Fundação Oswaldo Cruz (FIOCRUZ), v. VII(2); Jul -Out. 2000.

HARRIS, Marvin. 2001. Cultural Materialism: The Struggle for a Science of Culture. Altamira Press: Walnut Creek, CA, 2001.

IUMATTI, Paulo Teixeira. Caio Prado Jr. e as Ciências Naturais: sua apreensão das transformações epistemológicas da virada do século XIX. Estudos Sociedade e Agricultura, 14, abril 2000: 103-128.

LIMA, José Adil Blanco de. A Atualidade de Visão do Paraíso. Revista de Artes e Humanidades, 8, maioout 2011: 1-17. 
LOSADA, Janaina Zito. Historiografia brasileira e meio ambiente: as contribuições de Sérgio Buarque de Holanda e o debate contemporâneo da história ambiental. História, Ciências, Saúde - Manguinhos, Rio de Janeiro, v.23, n.3, jul-set. 2016, p.653-668

MURARI, Luciana. 2005. Excessivos benefícios sem grandes sacrifícios: natureza e colonização na obra de Sérgio Buarque de Holanda. ANPUH - XXIII Simpósio Nacional de História - Londrina, 2005.

PÁDUA, J. A. 2004. Um sopro de destruição: pensamento político e crítica ambiental no Brasil escravista, 1786-1888, 2.ed., Rio de Janeiro: Jorge Zahar, 2004.

. Ecologia à Brasileira II. 2005. Disponível em: http://www.oeco.org.br/colunas/joseaugusto-padua/17220-oeco-13882/ Acessado em: 20 de abril de 2017.

PRADO JÚNIOR, Caio. Formação do Brasil Contemporâneo. São Paulo: Companhia das Letras, 2011.

SANTOS, Ana Carolina V. R.2010. Ecologias em disputas: a Ecologia de Gilberto Freyre e a Ecologia Humana da Escola de Chicago (1930-1940). Revista Urutágua - acadêmica multidisciplinar DCS/UEM, № 21, maio/junho/julho/agosto 2010, p. 160-173.

SANTOS, Ana Carolina V. R. Natureza e modernidade em Sergio Buarque de Holanda: primeiras ideias. Ideias, Campinas (SP), n. 5, nova série, 2o semestre, 2012.

SOUZA, Francisco C. S. As contribuições de Caio Prado Júnior para a história ambiental no Brasil. Cronos, Natal-RN, v. 10, n. 1, p. 97-115, jan/jun. 2009.

STEWARD, Julian Haynes. 1955. Theory of Culture Change: The Methodology of Multilinear Evolution. University of Illinois Press, Champaing, IL: 1955.

TAVOLARO, Sérgio B. F. “À sombra do mato virgem..."Natureza e modernidade em uma abordagem sociológica brasileira. Ambiente \& Sociedade, Campinas, v. XI, n. 2, p.273-287, jul-dez, 2008.

TAVOLARO, Sérgio B. F. Freyre e DaMatta e o lugar da natureza na singularidade brasileira. Lua Nova, São Paulo, 83: 217-257, 2011.

TAVOLARO, Sérgio B. F. Gilberto Freyre e nossa modernidade tropical. Entre a originalidade e o desvio. Sociologias, Porto Alegre, ano 15, no 33, mai/ago. 2013, p. 282-317.

VIANA, Oliveira. 1932. Raça e assimilação. São Paulo, 1932.

ZARUR, George. 2015. A Guerra da Identidade: Raça e Mestiçagem no Pensamento Latino-Americano. Disponível em: http://www.georgezarur.com.br/artigos/166/a-guerra-da-identidade-raca-emesticagem-no-pensamento-latino-americano. Acesso em: 03 de abril de 2016. 